\title{
POLA KONSUMSI RUMAH TANGGA DI INDONESIA TAHUN 1990 - 2007
}

\author{
Veronika Nugraheni Sri Lestari ${ }^{\mathbf{1}}$ \\ Fakultas Ekonomi ${ }^{\mathbf{1}}$ Universitas Dr. Soetomo Surabaya \\ venugra@unitomo.ac.id ${ }^{1}$
}

\begin{abstract}
This study was aimed to know the short, medium and long effects of income to the household consumption in our country. The data was analyzed with a regression dynamic model, namely Distributed Lag Model.

Results of this research showed that the short effect of income to the household consumption use 0,3414 with $t=3,2909$ ( sig $=0,0050$ ), the medium effect of income to the household consumption were 0,7094 and the long effect of income to the household consumption was not found because Distributed Lag's Model have failed to explain the model on the second years.

Key Words : Distributed Lag Model, effects, the household, income, consumption

Tujuan penelitian ini adalah untuk mengetahui pengaruh-pengaruh jangka pendek, jangka menengah maupun jangka panjang pendapatan terhadap konsumsi rumah tangga di negara kita. Alat analisis yang di gunakan adalah model regresi dinamis Distributed Lag Model.

Hasil analisis yang didapat sebagai berikut : pengaruh jangka pendek pendapatan terhadap konsumsi sebesar 0,3414 dengan $\mathrm{t}$ hitung sebesar 3,2909 ( $\operatorname{sign}=0,0050$ ), pengaruh jangka menengah pendapatan terhadap konsumsi sebesar 0,7094 dan pengaruh jangka panjang tidak bisa diketahui karena model distributed lag telah gagal menerangkan model pada tahun kedua.
\end{abstract}

Kata kunci : Model Distribusi Lag, pengaruh, rumahtangga, pendapatan, konsumsi

\section{PENDAHULUAN}

\section{Latar Belakang}

Negara kita memiliki penduduk 200 juta lebih, angka ini terbilang sangat banyak. Jumlah penduduk yang terlalu banyak akan menghambat dalam pembentukan modal untuk melakukan investasi, yang selanjutnya bisa menjadi penghambat laju pembangunan.

Pelbagai literatur menyebutkan bahwa kecenderungan untuk mengkonsumsi ( Marginal Propensity to Consump $=M P C$ ) dibanyak negara berkembang berada diatas 0,6 . Nilai $M P C$ 
yang besar menandakan bahwa sebagian besar pendapatannya di pakai untuk konsumsi, sementara itu yang di pakai untuk menabung hanya sebagian kecilnya saja. Peneliti tertarik melakukan penelitian ini karena belum ada penelitian tentang pola konsumsi rumah tangga negara kita dengan memakai alat analisis model dinamis Distributed Lag Model.

Sistematika penelitian ini sebagai berikut : Pendahuluan ( Latar Belakang, Tujuan Penelitian, Perumusan Masalah ), Studi Pustaka ( Penelitian Terdahulu, Landasan Teori ), Hipotesis, Metodologi Penelitian ( Data dan Sumber Data, Alat Analisis ), Hasil dan Pembahasan, Simpulan dan Daftar Pustaka.

\section{Tujuan Penelitian}

Tujuan penelitian ini adalah :

1. Menguji pengaruh jangka pendek pendapatan terhadap konsumsi di negara kita.

2. Menguji pengaruh jangka menengah pendapatan terhadap konsumsi di negara kita.

3. Menguji pengaruh jangka panjang pendapatan terhadap konsumsi di negara kita.

\section{Perumusan Masalah}

1. Apakah ada pengaruh jangka pendek yang signifikan pendapatan terhadap konsumsi di negara kita?

2. Apakah ada pengaruh jangka menengah yang signifikan pendapatan terhadap konsumsi di negara kita?

3. Apakah ada pengaruh jangka panjang yang signifikan pendapatan terhadap konsumsi di negara kita? 


\section{STUDI PUSTAKA}

\section{Penelitian Terdahulu}

Lumadya Adi ( 1996 ), meneliti tentang pola konsumsi rumah tangga penduduk Jawa timur dan implikasinya dengan metode Ordinary Least Square mendapatkan hasil bahwa ada hubungan positif dan signifikan antara pendapatan dengan konsumsi dimana MPC $=0,66$.

Lumadya Adi ( 2002 ), meneliti tentang pola konsumsi rumah tangga di India dengan memakia alat analisis Partial Adjustment Model menadapatkan hasil bahwa : 1. Dalam jangka pendek pola konsumsi rumah tangga dipengaruhi secara positf dan signifikan oleh pendapatan, 2. Dalam jangka panjang pola konsumsi rumah tangga dipangaruhi secara positif namun tidak signifikan oleh pendapatan.

\section{Landasan Teori}

Teori yang di gunakan dalam penelitian ini adalah teori konsumsi dari Keynes, dimana konsumsi dipengaruhi oleh pendapatan dan keduanya memiliki hubungan yang positif, artinya apabila pendapatan mengalami kenaikan maka konsumsi juga mengalami kenaikan, jika Hubungan keduanya apabila di buat kedalam sebuah fungsi, maka konsumsi (Ct) merupakan fungsi pendapatan ( Yt ) atau

$$
\mathrm{Ct}=\mathrm{f}(\mathrm{Yt})
$$

Dimana:

Ct adalah konsumsi aras

Yt adalah pendapatan yang siap di belanjakan aras.

Kecenderungan mengkonsumsi ( Marginal Propensity to Consump $=$ MPC ) terhadap pendapatan berada diantara nol dengan satu atau $0<\mathrm{MPC}<1$. Dengan mengasumsikan bahwa 
pendapatan hanya di pakai untuk konsumsi dan tabungan, maka hubungan antara kecenderungan untuk menabung ( Marginal Propensity to Saving = MPS ) dengan kecenderungan mengkonsumsi ( MPC ) sebagai berikut :

$$
\begin{aligned}
& 1-\text { MPC }=\text { MPS sehingga } \\
& \text { MPC + MPS }=1
\end{aligned}
$$

\section{HIPOTESIS}

Hipotesis dalam penelitian ini adalah :

1. Ada pengaruh jangka pendek yang signifikan pendapatan terhadap konsumsi di negara kita.

2. Ada pengaruh jangka menengah yang signifikan pendapatan terhadap konsumsi di negara kita.

3. Ada pengaruh jangka panjang yang signifikan pendapatan terhadap konsumsi di negara kita.

\section{METODOLOGI PENELITIAN}

\section{Data dan Sumber Data}

Data yang dipakai dalam penelitian ini adalah data sekunder yang bersumber dari WWW.ADB.ORG/KEY INDICATORS 2008: COMPARING POVERTY ACROSS COUNTRIES: THE ROLE OF PUCHASING POWER PARITIES.

Variabel-variabel penelitian meliputi: Konsumsi rumah tangga ( private consumption) dan pendapatan nasional harga berlaku ( expenditure GDP at current market price ) dalam miliar rupiah tahun $1990-2007$. 


\section{Alat Analisis}

Penelitian ini menggunakan alat regresi linier dengan formula :

$$
\mathrm{Ct}=\alpha_{0}+\alpha_{1} \mathrm{Y}_{\mathrm{t}}
$$

Dimana :

$\mathrm{Ct}$ adalah konsumsi aras

Yt adalah pendapatan nasional aras.

Data time series kebanyakan tidak stasioner sehingga model statis pada persamaan (1) di ubah ke dalam model dinamis yaitu : Distributed Lag Model.

Selanjutnya pengolahan data memakai alat analisis model dinamis Distributed Lag Model dalam bentuk ( Gujarati 1995 : 585 )

$$
\mathrm{Ct}=\beta_{0}+\beta_{1} \mathrm{Y}_{\mathrm{t}}+\beta_{2} \mathrm{Y}_{\mathrm{t}-1}+\beta_{3} \mathrm{Y}_{\mathrm{t}-2}+\ldots \ldots+\mu_{\mathrm{i}}
$$

Dimana :

$\mathrm{Ct} \quad$ adalah konsumsi aras

Yt adalah pendapatan nasional aras.

Yt-n adalah pendapatan nasional periode sebelumnya

$\beta_{0} \quad$ adalah konstanta

$\beta_{1} \quad$ adalah pengaruh regresi jangka pendek atau short-run, impact, multiplier.

$\beta_{1}+\beta_{2} \quad$ adalah pengaruh jangka menengah atau interim, intermediate, multipliers

$\beta_{1}+\beta_{2}+\beta_{2}$ adalah pengaruh jangka panjang atau long-run, total, distribused-lag multipliers. 


\section{HASIL DAN PEMBAHASAN}

Data tahun 1990 - 2007 akan terlebih dahulu menggunakan model regresi statis dengan hasil sebagai berikut :

$\mathrm{Ct}=-20205,5+0,6695 \mathrm{Yt}$

$\mathrm{Se}=21993,58 \quad 0,0129$

$\mathrm{t}=-0,9187 \quad 52,06234$

Sign $=0,3719 \quad 0,0000$

Dari model (3) kita dapatkan bahwa pengaruh positif dan signifikan antara konsumsi dengan pendapatan di negara kita dengan nilia $\mathrm{MPC}=0,6695$ dan $\mathrm{t}$ hitung $=52,06234$ ( $\operatorname{sign} 0,0000)$.

Memakai model dinamis Distributed Lag Model dengan variabel bebas Yt dan Yt-1 medapatkan hasil sebagai berikut :

$\mathrm{Ct}=56,5495+0,3414 \mathrm{Yt}+0,3680 \mathrm{Yt}-1$

$\mathrm{Se}=18680,26 \quad 0,1037 \quad 0,1158$

$\mathrm{t}=0,0030 \quad 3,2909 \quad 3,1785$

Sign $=0,9976 \quad 0,0050 \quad 0,0062$

Dari model (4) kita dapatkan hasil bahwa pengaruh jangka pendek antara pendapatan dengan konsumsi sebesar 0,3414 . Angka 0,3414 ini bisa di maknai bahwa apabila ada kenaikan pendapatan sebesar 1 Rupiah maka akan di ikuti dengan kenaikan konsumsi sebesar 0,3414 Rupiah pada tahun yang sama. Angka 0,3680 bisa di maknai pendapatan yang akan terpakai konsumsi untuk tahun berikutnya sebesar 0,3680 Rupiah. Pengaruh jangka menegah antara pendapatan dengan konsumsi sebesar $(0,3414+0,3680)=0,7094$. 
Memakai model dinamis Distributed Lag Model dengan variabel bebas Yt, Yt-1dan Yt-2 mendapatkan hasil sebagai berikut :

$$
\begin{array}{lrrrc}
\mathrm{Ct}= & -1692,65+0,3454 \mathrm{Yt}+0,4108 \mathrm{Yt}-1-0,0550 \mathrm{Yt}-2 \\
\mathrm{Se}= & 19772,63 & 0,1073 & 0,1636 & 0,1439 \\
\mathrm{t}=-0,0856 & 3,2179 & 2,5113 & -0,3822 \\
\text { Sign }=0,9330 & 0,0062 & 0,0249 & 0,7080
\end{array}
$$

Model (5) mengatakan kepada kita bahwa model sudah tidak bisa dipakai sebagai model yang baik karena koefisien regresi telah berubah tanda yaitu semula positif menjadi negatif ( $-0,0550)$. Pengaruh jangka pendek, jangka menengah dan jangka panjang tidak bisa dicari dari model ini. Dengan demikian model yang baik adalah model (4).

\section{SIMPULAN DAN SARAN}

\section{Simpulan}

1. Koefisien regresi model statis sebesar 0,6695. Hal ini menunjukkan kepada kita, bahwa apabila ada kenaikan pendapatan sebesar 1 Rupiah maka akan di gunakan untuk keperluan menabung sebesar 0,6695 Rupiah.

2. Pengaruh jangka pendek pendapatan terhadap konsumsi sebesar 0,3414. Hal ini menunjukkan bahwa apabila pendapatan rumah tangga naik sebesar 1 Rupiah maka yang akan dipakai untuk konsumsi sebesar 0,3414.

3. Pengaruh jangka menengah pendapatan terhadap konsumsi sebesar $(0,3414+0,3680=$ 0,7094 ), artinya apabila ada kenaikan pendapatan sebesar 1 Rupiah, maka konsumsi pada tahun yang bersangkutan dan konsumsi 1 tahun berikutnya sebesar 0,7094 Rupiah. 
4. Kecenderungan untuk menabung pada tahun yang sama dan tahun berikutnya sebesar 0,2906 Rupiah.

\section{Saran}

1. Perlu ada pengurangan konsumsi untuk tahun - tahun yang akan datang.

2. Perlu konsumsi pelbagai macam produk pertanian tidak hanya beras saja, agar ada penghematan.

3. Perlu peningkatan tabungan agar investasi kelak semakin besar.

4. Peneliti berikutnya perlu menggunakan pelbagai alat analisis agar mendapatkan hasil yang terbaik. 


\section{DAFTAR PUSTAKA}

Gujarati, Damodar N., Basic Econometrics, Third Edition, McGraw-Hill, International Edition, 1995

Insukindro, Pelatihan metodologi Empiris: Ekonometrika Model Dinamis, Modul, PAU-Studi Pembangunan, 25-29 Juni 2001, Universitas Gadjah Mada, Yogyakarta, 2001

Lumadya Adi, Pola Konsumsi Rumah Tangga Jawa Timur dan Implikasinya, Hasil Penelitian, Fakultas Ekonomi Universitas Dr.Soetomo, Surabaya, 1996

Lumadya Adi, Pola Konsumsi Rumah Tangga di India Tahun 1975 - 1999, Jurnal Ekonomi, Bisnis dan Sosial ( JEB’s ), Fakultas Ekonomi Universitas Putra Bangsa, Surabaya, 2002

Mankiw, Gregory N., Macroeconomics, Second Edition, Worth Publisher, New York, USA, 1994

WWW.ADB.ORG/KEY INDICATORS 2008: COMPARING POVERTY ACROSS COUNTRIES: THE ROLE OF PUCHASING POWER PARITIES. 